\title{
A pós-graduação no processo formacional do bibliotecário: concepções e reflexões teóricas
}

\author{
Claudia Lourenço da Silva \\ Vanildo Pereira Pontes \\ Universidade Federal do Ceará - UFC, Brasil
}

\section{ANÁLISIS}

\begin{abstract}
Resumo
Objetivo: Apresentar o contexto informacional (através de concepções e reflexões teóricas) sobre a pós-graduação, biblioteconomia e bibliotecário, como processo formacional e educacional do profissional da informação. Método: seu processo metodológico dar-se-á na análise de revisão literária (artigos, internet e livros) dos temas apresentados, através de uma pesquisa exploratória dos temas estudados por diversos autores. Resultado: o artigo resultou na perspectiva de compreender a formação continuada do profissional como fator importante no desenvolvimento intelectual e racional. Conclusão: o estudo contribuirá para conhecimento, ampliação e fortalecimento dos cursos de formação universitária profissional, stricto e lato-sensu, como condição indispensável para que os bibliotecários se qualifiquem para as mudanças estruturais de seu trabalho na sociedade da informação.
\end{abstract}

Palavras-chave

Bibliotecário ; Biblioteconomia ; Educação continuada ; Pós-Graduação

\section{The posgraduate in the librarian formational process: concepts and theoretical reflections}

\section{Abstract}

Objective: To present the informational context ( through concepts and theoretical reflections ) on graduate school, library and librarian, as formational and educational process of the information professional. Method: its methodological process will occur in the literature review analysis ( articles, books and Internet ) of subjects presented through an exploratory research of the topics studied by several authors. Result: the article resulted from the perspective of understanding the continuing professional training as an important factor in the intellectual and rational development. Conclusion: The study will contribute to knowledge expansion and strengthening of professional university training courses, strict and broad sensu, as a prerequisite for librarians to qualify for structural changes of their work in the information society.

Keywords

Librarian ; Librarianship; Continuing education ; Posgraduate 


\section{Introdução}

Devido à globalização, os avanços tecnológicos e também ao risco do desemprego que a atual crise econômica gerou em todo o mundo, o mercado de trabalho vem se tornando mais competitivo e exigente. Na chamada Era da Informação, as pessoas não estão apenas valorizando a comunicação fácil, principalmente pela rede mundial de computadores, mas também há uma grande preocupação com a atualização do conhecimento.

A profissão do bibliotecário é bastante abrangente e possui diversas áreas de atuação, conseqüentemente o número de profissionais disponíveis no mercado é consideravelmente razoável. De acordo com levantamento feito pelo CFB (Conselho Federal de Biblioteconomia) em 2011, o Brasil 16332 profissionais bibliotecários. Por esse motivo é inegável a necessidade desses profissionais se qualificarem exemplarmente para que possam garantir a sua empregabilidade e evitar que profissionais de outras áreas ocupem cargos inicialmente destinados a outros profissionais.

Conscientes dessa situação, o número de profissionais pouco satisfeitos com a graduação, cresce a cada dia; eles estão sempre em busca de novos recursos para estarem melhor preparados para sua atuação no mercado de trabalho. Dentre esses recursos existem os programas de especialização, também conhecidos como cursos de pós-graduação lato sensu, que são destinados a profissionais graduados e que têm como objetivo a capacitação profissional em uma área específica.

Por meio da realização desses cursos os profissionais têm a oportunidade de se atualizar profissionalmente, de ampliar a empregabilidade, de aumentar o rendimento salarial, de estender seus contatos profissionais e aprimorar os conhecimentos adquiridos na graduação.

Esse artigo propõe fazer um estudo teórico sobre os profissionais bibliotecários, o mercado de trabalho, a educação continuada na pós-graduação e seus cursos; na perspectiva de fortalecer a participação deste profissional na sociedade da informação, sob a importância do mesmo na disseminação da informação.

\section{Referencial teórico}

\subsection{A importância da educação continuada na carreira profissional}

Segundo Araújo (2006), novas realidades surgem a todo o momento, exigindo por parte das empresas, técnicas direcionadas a rápidas adaptações, com o intuito de evitar perda da qualidade e queda na imagem da organização. Assim como as empresas, os profissionais também precisam se adequar às novas realidades, buscando aprimorar e atualizar os seus conhecimentos teóricos e práticos para que possam garantir o seu espaço no mercado de trabalho.

Devido ao número de profissionais disponíveis, é de fundamental importância que os bibliotecários e os futuros bibliotecários se conscientizem da necessidade de se atualizarem e se especializarem em uma área, como uma forma de ter uma vantagem competitiva diante da concorrência. Neste sentido Lévy (1994, p.54 apud ABREU; GONÇALVES; PAGNOZZI, 2003, p. 5) afirma que: "[...] o aumento da competitividade, aliado ao contínuo avanço da tecnologia, faz com que os 'conhecimentos tenham um ciclo de renovação cada vez mais curto'[...]". 
A educação continuada apresenta-se como uma ferramenta que pode ajudar estes profissionais a se qualificarem para o atual mercado de trabalho. De forma conceitual, a educação continuada pode ser definida segundo Crespo, Rodrigues e Miranda (2006, p. 3) como sendo "as atividades educacionais que têm por objetivo atualizar e desenvolver o conhecimento e as habilidades profissionais, de forma a permitir ao profissional um melhor desempenho da sua função [...]". Já de acordo com Mundim (2002, apud SALM; HEIDEMANN; MENEGASS, 2006, p. 3) educação continuada é "[...] o conjunto de práticas educacionais planejadas para promover oportunidades de desenvolvimento ao trabalhador, visando ajudá-lo a atuar de forma mais eficaz em sua vida 'institucional' [...]."

Segundo Santos (1999, apud TEIXEIRA, 2005) o principal motivo da educação continuada é evitar que os profissionais se desatualizem técnica, cultural e profissionalmente, para que eles não percam a sua capacidade de exercer a profissão com eficiência e para que eles não venham a se sentir incapazes profissionalmente.

Os cursos de pós-graduação são apenas uma das formas de educação continuada disponíveis para os profissionais, pois conforme Cunha (1984, apud MIRANDA; SOLINO, 2006), qualquer aprendizagem formal ou informal realizada após concluir a primeira graduação é definida como educação continuada.

\subsection{Pós-graduação: uma modalidade de educação continuada para formação do bibliotecário}

O conhecimento é fator de suma importância nos mais diversos âmbitos sociais. A busca do acesso igualitário ao conhecimento proporcionado pelas tecnologias da informação tem como objetivo diminuir as dificuldades a este acesso, driblando aquelas impostas por fatores como a falta de oportunidades, infraestrutura, recursos, etc.

Manter-se atualizado, não é premissa exclusivamente pessoal, pois, além da competitividade, fator inerente à sociedade atual, há que considerar a necessidade de cada indivíduo participar, social ou economicamente, do desenvolvimento da ciência, das pesquisas e da criação e implementação de novas ideias em prol do bem comum. Destacam-se, entre outras razões para a busca da educação continuada, tais como: concluída a formação básica (Graduação), temos a pós-graduação para aperfeiçoar-se ou atualizar-se; que auxiliará em atuar em campos específicos, complementar seus conhecimentos, especializando-se na área de interesse.

A educação continuada pode ser definida como as atividades educacionais que têm por objetivo atualizar e desenvolver o conhecimento e as habilidades profissionais, de forma a permitir ao profissional um melhor desempenho da sua função. Pode, ainda, ser conceituada como "O aprendizado formal e informal pelo qual um indivíduo procura se atualizar ou avançar nos seus estudos, atitudes e conhecimentos e por meio disso aprimorar a suas competências relacionadas com o trabalho no presente e para o futuro" (Saechan, 2005, p. 26, tradução nossa).

Outros autores a definem como: "[...] educação permanente, educação recorrente, educação contínua, educação continuada, formação continuada. Promover esse crescimento profissional é tarefa da instituição em que o indivíduo está ligado, mas é também tarefa individual” (Pereira \& Rodrigues, 2002, p. 222).

Entretanto, não se deve considerar a educação continuada como apenas um treinamento ou atualização, mas, sim, um acompanhamento das alterações na sociedade e dos avanços tecnológicos proporcionando, também, 
desenvolvimento profissional contínuo e adquirindo contornos de solução para atualização e qualificação do profissional da informação (Pereira \& Rodrigues, 2002). Afinal, “[...] a educação contínua tem como objetivo o desenvolvimento individual e, em uma visão mais ampla, é parte do sistema educacional global e uma forma de desenvolvimento integral do indivíduo e da sociedade" (Zanaga, 1989, p. 56).

Como modalidade de educação continuada destaco a pós-graduação, cujos cursos de mestrados e doutorados em Biblioteconomia e Ciência da Informação que apresentou-se seus primeiros cursos strictu sensu na década de 70 , promovendo o desenvolvimento da pesquisa, ampliando o crescimento profissional e o surgimento dos periódicos científicos.

A seguir abordaremos o contexto informacional sobre pós-graduação, biblioteconomia e bibliotecário.

\subsection{Breve histórico da pós-graduação no Brasil}

Segundo Santos (2003) os primeiros passos da pós-graduação no Brasil foram dados de acordo com a seguinte cronologia:

$\mathrm{Na}$ década de 1930, através de uma iniciativa do Estatuto das Universidades Brasileiras foram implantados cursos de pós-graduação no curso de direito na Universidade do Rio de Janeiro, na Faculdade Nacional de Filosofia e na Universidade de São Paulo, baseados nos modelos europeus;

$\mathrm{Na}$ década de 1940, foi utilizado pela primeira vez o termo "pós- graduação" No Artigo 71 do Estatuto da Universidade do Brasil;

$\mathrm{Na}$ década de 1950, foram firmados os primeiros acordos entre Estados Unidos e Brasil que estabeleceram convênios entre escolas e universidades norte-americanas e brasileiras por meio do intercâmbio de estudantes, pesquisadores e professores.

Na década de 1960, houve o grande impulso para os cursos de pós-graduação, pois devido a um convênio com a Fundação Ford, na área de Engenharia, surgiu a Comissão Coordenadora dos Programas de Pós-Graduação em Engenharia (COPPE), houve a implantação do Mestrado em Matemática da Universidade de Brasília (UnB) e implantação do mestrado e doutorado na Escola Superior de Agricultura de Viçosa e Universidade Federal Rural do Rio de Janeiro. E em 1965, os cursos de pós-graduação foram formalmente implantados no Brasil através do Parecer 977 do Conselho Federal de Educação.

Ainda segundo Santos (2003), duas tendências marcaram a pós-graduação brasileira: a européia, (principalmente na USP) e a norte-americana (ITA, Universidade Federal de Viçosa e Universidade Federal do Rio de Janeiro), sendo esta última a que deixou mais marcas e foi adotada pelo governo quando a pós-graduação foi formalizada no Brasil.

\subsection{Os tipos de pós-graduação no processo de formação profissional}

De acordo com o Ministério da Educação e Cultura (MEC), os cursos de pós- graduação abrange os programas de mestrado e doutorado, cursos de especialização que incluem os cursos designados como MBA - Master Business 
Administration, aperfeiçoamento e outros. E são destinados a candidatos diplomados em cursos de graduação e que atendam às exigências das instituições de ensino.

De acordo Santos (2000), o parecer define a pós-graduação lato sensu como os cursos de especialização e aperfeiçoamento, que geralmente têm objetivo técnico-profissional específico, sem abranger o campo total do saber em que se insere a especialidade.

De acordo com Machado (2003), o Programa Nacional de Capacitação de Professores de instituições de Ensino Superior (PROCAPIES) divide os cursos de lato sensu em 2 (duas) modalidades:

1. Aperfeiçoamento - São cursos que visam à ampliação e desenvolvimento de conhecimento de metodologia do ensino superior, de metodologia científica e de conteúdos específicos. E têm com carga horária mínima de 180 horas.

2. Especialização - São cursos que buscam aprofundar os conhecimentos teóricos e práticos, em setores específicos do saber, metodologia do ensino superior e em metodologia científica. E têm carga horária mínima de 360 horas.

Os cursos de pós-graduação latu sensu têm com objetivo atender a uma demanda específica do mercado de trabalho, aprofundando e completando conhecimentos, habilidades e atitudes necessárias para os profissionais de acordo com o seu perfil técnico-profissional.

Segundo Gomes (1999, p.1 apud MACHADO, 2003, p.64), a história da pós- graduação latu sensu no Brasil pode ser caracterizada como nebulosa, porque o Parecer 677/65, definiu a pós-graduação sticto sensu muito bem, já os cursos de pós-graduação latu sensu foram apenas conceituados e divididos em duas categorias.

A pós-graduação sctrito sensu abrange os programas de mestrado, que geralmente têm duração de 2 anos e como requisito para aprovação a defesa de uma dissertação e os programas de doutorado, com duração de 4 anos e como requisito para aprovação a defesa de uma tese.

No Brasil existem dois tipos de mestrado: Mestrado acadêmico: que tem com objetivo formar professores para o ensino médio e superior e o Mestrado profissional: que tem como objetivo a qualificação profissional em alto nível.

Segundo Santos (2000), o Parecer 977/65 define os programas de doutorado como sendo cursos que têm como objetivo proporcionar formação cientifica ou cultural ampla e aprofundada, através do desenvolvimento da capacidade de pesquisa e do poder de criar.

Dentro dos programas de doutorado também existe o programa pós- doutorado que tem como finalidade atualizar os conhecimentos adquiridos no doutorado e normalmente tem duração de um ano.

\subsection{Biblioteconomia: concepções informacionais}

Em 1911 foi estabelecido o curso para formação de bibliotecários no Brasil, sob a responsabilidade da Biblioteca Nacional do Rio de Janeiro (TARGINO, 2006). O primeiro no Brasil e na América do Sul e o 
terceiro no mundo. O programa deste curso se inspirava no modelo francês (École de Chartre) com ênfase no cultural e no informativo, uma fase humanista na qual seus profissionais eram ilustres escritores, historiadores, literatos, pessoas cultas em geral.

Em 1929 a Universidade de Mackenzie, em São Paulo, criou um curso no modelo norte-americano e abriu a escola para alunos recém-saídos do curso secundário, o atual ensino médio, enfatizando aspectos técnicos da profissão.

O bibliotecário erudito, guardião e preocupado com problemas culturais, formado segundo os padrões da Biblioteca Nacional, cedeu lugar, nesta segunda geração, ao profissional técnico, voltado para o desempenho de atividades técnicas, para o trabalho interno de organização da biblioteca, mas despreparado para o trato de problemas de cultura e de auxílio aos leitores. (OLIVEIRA, 1983, p. 06).

Mais tarde em 1936 a Prefeitura de São Paulo criou um curso de Biblioteconomia, sendo este em 1940 incorporado à Escola de Sociologia e Política de São Paulo, onde está até hoje. Esta escola abriu um Curso de Atualização Profissional, onde o criador da escola Rubens Borba, convidou bibliotecários de todo o país, assim estes retornando aos seus estados seriam bases para a criação de cursos e escolas de Biblioteconomia, principalmente nas Universidades Federais.

Na Universidade Federal do Rio Grande do Sul, Escola de Biblioteconomia e Documentação surgiu em 1947, hoje com o nome de Faculdade de Biblioteconomia.

Muitos outros cursos de Biblioteconomia surgiram desde então no país, assim como uma variação na duração dos cursos e nos currículos, visto que não havia normas que a regessem. E assim em 1959 a Federação Brasileira de Associações de Bibliotecários empenhou-se na padronização dos cursos.

Apenas em 1962 foi criada a lei que garante o exercício da profissão aos que possuem diploma de curso regular de Biblioteconomia.

$\mathrm{Na}$ década de 70 a criação de seis cursos de mestrado, o surgimento de revistas especializadas e a expansão de oportunidades de emprego, deram novo impulso a Biblioteconomia. Somente na década de 80 surgem cursos de doutorados na área da Biblioteconomia.

Desde sua criação até hoje, muitas mudanças ocorreram e transformaram as práticas da biblioteconomia. Dos velhos e pesados livros que os bibliotecários consultavam e que eram suas ferramentas de trabalho, agora sobrou pouco ou quase nada. Basta um clique para acessar a informação onde quer que ela esteja. Através da internet a biblioteconomia evoluiu, ou pelo menos deveria evoluir. Com as redes de cooperação o intercâmbio de informações aumentou e contribui para a otimização do trabalho bibliotecário. Nossas antigas fichas e seus arquivos agora foram substituídos por uma máquina, o computador.

Claro que ainda há os catálogos manuais e as fichas, mas em muitas bibliotecas essa realidade já é diferente, graças aos esforços de seus bibliotecários, que mesmo com dificuldades buscam mantê-las atualizadas. Assim, passamos de guardiões do livro para disseminador da informação. Esta agora passa a ser nossa realidade. 


\subsubsection{Profissionais Bibliotecários: reflexões teóricas}

Segundo a Classificação Brasileira de Ocupações (CBO, 2007), os profissionais bibliotecários "Trabalham em biblioteca se centros de documentação e informação na administração pública e nas mais variadas atividades do comércio, indústria e serviços, com predominância nas áreas de educação e pesquisa.". Estes podem trabalhar vinculados a uma empresa ou como autônomos. Suas funções podem ser executadas tanto de forma presencial como à distância e as condições de trabalho são variadas, desde locais com pequeno acervo e sem recursos informacionais a locais que trabalham com tecnologia de ponta. Ainda conforme a CBO (2007), são consideradas como atividades inerentes ao profissional:

- disponibilizar informação em qualquer suporte;

- gerenciar unidades, redes e sistemas de informação;

- tratar tecnicamente recursos informacionais;

- d desenvolver recursos informacionais;

- disseminar informação;

- desenvolver estudos e pesquisas;

- prestar serviços de assessoria e consultoria;

- realizar difusão cultural;

- desenvolver ações educativas;

- demonstrar competências pessoais.

O profissional deve estar atento às necessidades de sua instituição e das mudanças que têm constantemente modificado o modo de realizar suas tarefas. É ele muitas vezes o elo entre o "modo de fazer" e o "novo". O profissional deve aliar a sua experiência acadêmica, de trabalho e suas competências pessoais para atender de forma eficiente e eficaz seus usuários e sua empresa. Segundo o CBO (2007), ele deve ainda possuir e demonstrar essas competências pessoais:

- liderar equipes;

- trabalhar em equipe e em rede;

- demonstrar capacidade de análise e síntese;

- demonstrar conhecimento de outros idiomas;

- demonstrar capacidade de comunicação;

- demonstrar capacidade de negociação;

- agir com ética;

- demonstrar senso de organização; 
- demonstrar capacidade empreendedora;

- demonstrar raciocínio lógico;

- demonstrar capacidade de concentração;

- demonstrar pró-atividade;

- demonstrar criatividade.

Juntamente com suas competências pessoais que o bibliotecário deve possuir e demonstrar como as citadas acima, outras aparecem e também estão diretamente relacionadas com a formação do bibliotecário. Este fato faz com que o bibliotecário tenha um diferencial em relação aos demais profissionais, pois, como conseqüência da sua formação, manuseia correta e eficazmente os conteúdos informacionais. Neves e Longo (1999/2000) relacionam alguns diferenciais que estão diretamente relacionados com a formação do bibliotecário:

- reconhecem a informação útil;

- classificam, representam e armazenam informações;

- estruturam, catalogam e analisam criticamente informações;

- possuem conhecimentos de softwares específicos de armazenagem de informações;

- localizam informações relevantes;

- dominam sistemas de indexação;

- avaliam os efeitos do uso da informação.

Com a experiência de saber reconhecer e tratar a informação de maneira correta, o profissional fornece subsídios para o aprimoramento e crescimento de sua empresa através da informação. Assim, esses profissionais "Na era da informação [...] são essenciais ao efetivo funcionamento das organizações [...]" (FERREIRA, 2003, p. 45). São eles com suas competências que, muitas vezes, dão suporte ao pleno funcionamento das empresas em que atuam, visto que, conforme Ferreira (2005, p. 19), ao atenderem as necessidades de informações, faz com que estas se tornem uma vantagem competitiva para essas organizações. "O conhecimento é atualmente fator essencial em todas as etapas do processo produtivo, desde a pesquisa básica até o marketing final e assistência ao consumidor." (TAKAHASHI, 2000, p. 17).

Aliar competências informacionais, pessoais e acadêmicas, é o meio de suprir e elevar o grau de satisfação das empresas em que os profissionais da informação estão inseridos.

Se trata de un estudio descriptivo, transversal de forma retrospectiva donde se han analizado los artículos publicados en la Revista CorSalud en el periodo comprendido entre el primer trimestre del año 2009 y el primer trimestre del año 2013 ambos inclusive. 


\section{Considerações finais}

Entendemos que a educação continuada e permanente, deve envolver não apenas programas de treinamento e reciclagem para qualificação profissional e permanência no mercado de trabalho, mas também deve gerar no indivíduo um processo, assistido e orientado, aprender a aprender, para que ele possa continuamente autoformar-se e capacitar-se para ser agente de seu desenvolvimento pessoal e consequentemente social.

Concluímos que esse processo de formação profissional deve gerar um exercício unitário do pensar e do fazer, necessário para a dignificação e humanização do trabalho. Trabalho que deve se pautar em critérios humanos ao decidir sobre o que, como e para que fazer e não exclusivamente em critérios econômicos.

A pós-graduação (especializações, mestrados e doutorados), se apresenta como o nível em que o profissional (já graduado) deverá tomar consciência da importância e necessidade desse processo. Apesar da crítica inerente ao sistema educacional e em especial às universidades federais, a pós-graduação no Brasil, tem contribuído significativamente para o aumento de titulação e qualificação para o mercado de trabalho, principalmente de pesquisadores, em todas as grandes áreas do conhecimento.

Esperamos assim, através deste artigo, contribuir para conhecimento, ampliação e fortalecimento dos cursos de formação universitária profissional, stricto e lato-sensu, como condição indispensável para que os bibliotecários se qualifiquem para as mudanças estruturais de seu trabalho na sociedade da informação.

\section{Bibliografia}

ABREU, A. F.; GONÇALVES, C. M.; PAGNOZZI, L. Tecnologia da informação e educação corporativa: contribuições e desafios da modalidade de ensino-aprendizagem à distância no desenvolvimento de pessoas. Disponível em:

< http://www.bomjesus.br/publicacoes/pdf/revista PEC 2003/2003 ti educacao coporativa.pd f >. Acesso em: 18 mar. 2012.

ARAÚJO, L. C. G. de. (2006). Gestão de pessoas. São Paulo: Atlas.

BAP̄TISTA, Sofia Galvão. (2002). Habilidades necessárias para o profissional atuar na era da informação: uma reflexão sobre as tendências do mercado. In: CONGRESSO DE BIBLIOTECONOMIA E DOCUMENTAÇÃO E CIÊNCIA DA INFORMAÇÃO, 20., 2002. Anais eletrônicos... Fortaleza: ABC.

BRASIL. Ministério do Trabalho e Emprego. Classificação brasileira de ocupações. Disponível em: <http://www.mtecbo.gov.br>. Acesso em: 18 mar. 2012.

BRASIL, Ministério da Educação e Cultura. Pós-graduação latu sensu e stricto sensu. Disponível em< http://portal. mec.gov.br/index.php?ltemid=349\&id=387\&option=com content >. Acesso em: 18 mar. 2012.

CONSELHO FEDERAL DE BIBLIOTECONOMIA. Disponível em:_<http://www.cfb.org.br/ >. Acesso em: 18 mar. 2012.

CRESPO, I.M.; RODRIGUES, A.V. F; MIRANDA, C.L. Educação continuada para bibliotecários: características e perspectivas em um cenário de mudanças. Disponível em: < http://eprints.rclis.org/archive/00008443/01/25 08.pdf>. Acesso em: 18 mar. 2012. 
FERREIRA, Danielle Thiago. Profissional da Informação: perfil de habilidades demandadas pelo mercado de trabalho. (2003). Ciência da Informação, Brasília, DF, v. 32, n. 1, p. 42-49, jan./abr.

FERREIRA, Danielle Thiago. (2005). Profissional da informação e a gestão do conhecimento: perfil de habilidades demandadas por empresas de recrutamento e seleção de recursos humanos. In: SOUTO, Leonardo Fernandes (Org.). O profissional da informação em tempo de mudanças. Campinas, SP: Alínea. cap. 1, p. 14-27.

KRUEL, Inês Rosito Pinto et al. (2000). Mercado de trabalho do bibliotecário em Porto Alegre. Revista de Biblioteconomia e Comunicação, Porto Alegre, v. 8, p. 125-134, jan./dez.

LOUREIRO, Mônica de Fátima; JANNUZZI, Paulo de Martino. (2007). Profissional da informação: análise da inserção no mercado de trabalho brasileiro. Perspectivas em Ciência da Informação, Belo Horizonte, v. 12, n. 2, p. 23-48, maio/ago.

MACHADO, M. R. (2003). O resultado econômico-financeiro proporcionado aos profissionais mediante conclusão de cursos de pósgraduação latu sensu em contabilidade, 1988-2001. In: Conceito, origem e evolução da pós-graduação lato sensu. Paraíba. Disponível em: <http://www.unb.br/cca/posgraduacao/mestrado/dissertacoes/mest dissert 017.pdf> . Acesso em: 19 mar. 2012.

MIRANDA, A. C.; SOLINO, A. S. Educação continuada e mercado de trabalho: um estudo sobre os bibliotecários do estado Rio Grande do Norte. Disponível em: <http://www.scielo.br/scielo.php? pid=S1413-99362006000300007\&script=sci arttext >. Acesso em: 19 mar. 2012.

MORIGI, Valdir José; SILVA, Magali Lippert da. (2005). Paradigma tecnológico e representações sociais dos bibliotecários sobre seu perfil e suas práticas no contexto da sociedade da informação. Revista Informação e Sociedade: estudos, João Pessoa, v. 15, n. 1, p. 123-145, jan./jun.

MUELLER, Suzana Pinheiro Machado; BAPTISTA, Sofia Galvão Baptista. (2000). Mercado de trabalho do bibliotecário em Brasília: estudo das características e da evolução dos empregos ocupados pelos profissionais formados pelo curso de graduação em Biblioteconomia da Universidade de Brasília. In: CONGRESSO DE BIBLIOTECONOMIA E DOCUMENTAÇÃO, 19., 2000, Porto Alegre. Anais eletrônicos... Porto Alegre: CRB, 32 p

NEVES, Elisabete da C.; LONGO, Rose Mary J. (1999/2000). Atuação do profissional da informação na gestão do conhecimento. Revista de Biblioteconomia de Brasília, Brasília, DF, v. 23/24, n. 2, p. 161-172. (Número especial).

Pereira, A. M.; \& Rodrigues, R. (2002). Educação continuada do catalogador: o caso da Universidade do estado de Santa Catarina. Revista ACB, Florianópolis, v. 7, n. 1, p. 219-239.

OLIVEIRA, Zita Catarina Prates de. (1983). O bibliotecário e sua auto-imagem. São Paulo: Pioneira. cap, 1. p. 1-13.

SALM, J. F; HEIDEMAN, F. G.; MENEGASSO, M. E. Política de educação continuada corporativa: capacitação gerencial em empresa pública. Disponível em: < http://www. portalseer.ufba.br/index.php/revistaoes/article/viewArticle/10862 >. Acesso em: 20 mar. 2012.

SANTOS, C. M. dos. Tradições e contradições da pós-graduação no Brasil. Disponível em: <http://www.scielo.br/scielo.php?pid=S0101-73302003000200016\&script=sci arttext> Acesso em: 20 mar. 2012.

SANTOS, A. C. P. dos. (2000). Analise setorial: ensino superior. Gazeta mercantil, v. 2. p. 238-239.

SAECHAN, C. The needs of continuing education for academic librarians in the South of Thailand. Malaysian Journal of Library \& Information Science. Disponivel em: < http://mailis.fsktm.um.edu.my/detail.asp?AID=328 >. Acesso em: 20. mar. 2012.

TAKAHASHI, Tadao (Org.). (2000). Sociedade da informação no Brasil: livro verde. Brasília: Ministério da Ciência e Tecnologia. $203 \mathrm{p}$.

TARGINO, Maria das Graças. (2006). Olhares e fragmentos: cotidiano da biblioteconomia e ciência da informação. Teresina: EDUFPI. 266 p.

TEIXEIRA, E. B. Educação continuada corporativa: aprendizagem e desenvolvimento humano no setor metal-mecânico. Disponível em: <http://www.tede.ufsc.br/teses/PEPS4612.pdf> . Acesso em: 20 mar. 2012.

TOMAÉL, Maria Inês; ALVARENGA, Georfravia Montoza. (2000). Profissional da informação: seu espaço e atuação em empresas industriais. Perspectivas em Ciência da Informação, Belo Horizonte, v. 5, n. 1, p. 81-90, jan./jun.

ZANAGA, M. P. (1989). Educação contínua: atitudes e experiências dos bibliotecários do sistema de bibliotecas da UNICAMP Transinformação, Campinas, v. 1, n. 3, p. 55-74, set./dez. 


\section{Dados dos autores}

Claudia Lourenço da Silva

Bibliotecária. Possui graduação em Biblioteconomia pela Universidade Federal do Ceará (2010), atuando principalmente nos seguintes temas: biblioteconomia e automação de bibliotecas.

claudia.silva21@yahoo.com.br

Vanildo Pereira Pontes

Bibliotecário na Universidade de Pernambuco, Campus Salgueiro. Possui graduação em Biblioteconomia pela Universidade Federal do Ceará (2010), atuando principalmente nos seguintes temas: biblioteconomia, técnicas biblioteconômicas, automação de bibliotecas e biblioteca escolar e universitária.

vanildopontes@hotmail.com

Recibido - Received: 2013-05-18

Aceptado - Accepted: 2013-12-30

\section{(c) $)$ EY}

This work is licensed under a Creative Commons Attribution 4.0

United States License.

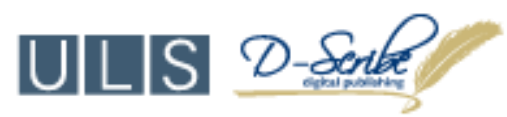

This journal is published by the University Library System of the University of Pittsburgh as part of its D-Scribe Digital Publishing Program and is cosponsored by the University of Pittsburgh Press. 